\title{
VIOLÊNCIA SEXUAL CONTRA CRIANÇAS E ADOLESCENTES: CARACTERÍSTICAS DO ABUSO E DA DENÚNCIA NO ANO DE 2015, EM FEIRA DE SANTANA, BAHIA.
}

\author{
$\underline{\text { Daniela Pereira Portugal Souza }}{ }^{1}$; Maria Conceição Oliveira Costa ${ }^{2}$; \\ 1. Bolsista PIBIC/PROBIC, Graduanda em Psicologia, Universidade Estadual de Feira de Santana, e-mail: \\ danielapportugal@gmail.com \\ 2. Orientadora, Departamento de Saúde, Universidade Estadual de Feira de Santana, e-mail: oliveiramco69@gmail.com.
}

PALAVRAS-CHAVE: VIOLÊNCIA SEXUAL; CRIANÇAS; ADOLESCENTES.

\section{INTRODUÇÃO}

Ao decorrer de todo o ciclo vital, o homem encontra-se em desenvolvimento, e crianças e adolescentes vivenciam descobertas referentes ao mundo o qual as cercam, o que promove conquistas, entretanto, também as inserem condição de vulnerabilidade, pois encontram-se suscetíveis às relações estabelecidas com seu meio, de forma mais intensa que o adulto (PAPALIA; OLDS, 2000). O Estatuto da Criança e do Adolescente (lei 8.069/90) considera criança, o indivíduo até onze anos de idade, e adolescente as pessoas que possuem entre doze e dezoito anos de idade (BRASIL, 2010).

Segundo o Ministério da Saúde (BRASIL, 2004), a violência sexual contra crianças e adolescentes é considerada problema referente à saúde pública, geralmente ocorre entre "uma criança ou adolescente e alguém em estágio psicossexual mais avançado do desenvolvimento, no qual a criança ou adolescente estiver sendo usado para estimulação sexual do perpetrador" (HABIGZANG et al., 2005; HABIGZANG et al., 2005, p. 341; SENA et al., 2018).

Dessa forma, pode apresentar-se com contato através de "interação sexual, pode incluir toques, carícias, sexo oral ou relações com penetração (digital, genital ou anal)" (HABIGZANG et al., 2005, p. 341) e sem contato, como no voyerismo, assédio e exibicionismo, e, geralmente ocorrem utilizando-se de força física, coerção psicológica sob a forma de ameaça, sedução, etc. Os contextos de ocorrência do abuso sexual são classificados em extrafamiliar e intrafamiliar. O abuso sexual extrafamiliar conforme aponta Santos (2011, p. 65), pode ocorrer "nos espaços de socialização das crianças e adolescentes, mas também inclui pessoas nas quais o menor conhece e em quem confia", como também em ambiente não conhecido pela criança e advindo de pessoa estranha ao menor e à família (NEVES et al., 2010). O abuso sexual intrafamiliar é "considerada como incestuoso, ocorre no espaço social interno da família, seja ela biológica ou adotiva." (SANTOS, 2011, p. 65).

A presente pesquisa teve como objetivo geral estudar características das denúncias e dos abusos sexuais perpetrados contra crianças e adolescentes, registradas em 2015, nas Delegacias de Polícia Civil (DAI, DERCA e DEAM), de Feira de Santana, Bahia.

\section{MÉTODO}

Estudo de corte transversal, com dados secundários dos casos de violação sexual (abuso e exploração comercial) de crianças e adolescentes, obtidos nos Boletins de Ocorrência e Relatórios dos Inquéritos Policiais da Delegacia de Polícia Civil, Delegacia Especializada de atendimento à Mulher - DEAM, Delegacia de Repressão ao Crime Contra a Criança e o Adolescente - DERCA, Delegacia do Adolescente Infrator- DAI, referente ao ano de 2015. Como instrumento de coleta de dados utilizou-se um formulário estruturado para atender aos objetivos da pesquisa. Os dados foram analisados por meio do Programa Statistical Package for Social Science SPSS, versão 10.0 for Windows (1998). 
A presente pesquisa integra o projeto "Rede de proteção e prevenção da violência e garantia dos Direitos Humanos: Integração Universidade e Sistemas de Segurança Pública, atendimento e defesa da infância, adolescência e juventude", que foi aprovado pelo Comitê de Ética em Pesquisa da Universidade Estadual de Feira de Santana, com protocolo de nº143/2010 (CAAE no 0141.0.059.000-10), em conformidade com a resolução no 466/12 do Conselho Nacional de Saúde. A coleta de dados foi autorizada pela Coordenação Regional da Policia Civil de Feira de Santana (Departamento de Polícia do Interior - DEPIN; $1^{\text {a }}$ Coordenaria de Polícia do Interior $-1^{\text {a }}$ COORPIN).

\section{RESULTADOS E DISCUSSÃO}

Em relação ao ano de 2015, período no qual compreende a pesquisa, foram notificados 81 casos de violência sexual contra crianças e adolescentes, registradas nas Delegacias de Polícia Civil e Especializadas, na cidade de Feira de Santana, Bahia. No que se refere às características das vítimas, a maioria das vítimas são do sexo feminino $(87,7 \%)$; a faixa etária com maior número de ocorrências foi de 12 a 17 anos $(56,6 \%)$, entretanto, as vítimas que estavam entre 2 e 12 anos também representam um percentual relevante $(43,2 \%)$. Grande parte das vítimas frequentava a escola $(89,6 \%)$, e 64,99\% moravam com a mãe, enquanto que $22,1 \%$ residiam com os genitores. Em estudo realizado no município de Londrina-PR, o percentual maior correspondeu às vítimas sexo feminino $(74,2 \%)$ (MARTINS; JORGE, 2010). Além disso, em pesquisa realizada em Porto Alegre, as meninas foram 75\% das vítimas (PELISOLI; PICCOLOTO, 2010). Entretanto, as vítimas do sexo masculino correspondem a 12,3\% dos casos, o que constitui-se como um avanço, pois a violência sexual pode estar ligada às questões de gênero e contribuir para a manutenção do tabu (ALMEIDA; PENSO; COSTA, 2009). Em estudo realizado em capitais brasileiras, verificou-se que $43,8 \%$ dos adolescentes sofreram violência sexual (MINAYO; ASSIS; NJAINE, 2011). Além disso, dados do Sistema de Vigilância de Violência e Acidentes, entre 2009 e 2010, indicam que 35,6\% das notificações foram de queixas de violência contra até nove anos (BRASIL, 2013).

Enquanto isso, no presente estudo, o abuso sexual foi o mais frequente em $96,3 \%$ das ocorrências, porém também foram denunciados casos de violência sexual com fins comerciais $(3,7 \%)$. Ressalta-se que Feira de Santana é considerada como zona de risco para a exploração sexual crianças e adolescentes, em decorrência da localização e proximidade da capital do estado (Salvador) (LEAL, 2003). Em pesquisa realizada sobre exploração sexual, realizada com caminhoneiros brasileiros, eles indicaram que a exploração pode ocorrer por necessidades financeiras da criança e da família (39\%) (MORAIS et al., 2007). Destaca-se que o contexto da violência sexual extrafamiliar foi o mais frequente $(61,7 \%)$, porém o contexto intrafamiliar também indica relevância $(38,3 \%)$. Em pesquisa realizada em Porto Velho, a maior frequência da violência sexual ocorreu no contexto extrafamiliar (MIRANDA et al., 2014). Entretanto, estudo realizado em Londrina indicou que 58,6\% dos agressores eram familiares ou faziam parte da família, e 35,5\% dos agressores eram conhecidos da vítima (MARTINS; JORGE, 2010).

Ademais, em relação ao vínculo com a vítima, 28,4\% dos agressores foram vizinhos/ pessoas da comunidade, $21 \%$ eram desconhecidos, os padrastos/madrastas representaram $17,3 \%$, o pai aparece em $7,4 \%$ das denúncias, as mães representam $2,5 \%$, enquanto que outros familiares também foram abusadores (12,3\%). Os amigos, colegas/namorados também apareceram como agressores nas denúncias $(11,1 \%)$. Cabe salientar $26 \%$ das ocorrências apresentaram mais de um agressor. Quanto ao local de ocorrência da violência, a maioria aconteceu em residências ou ambiente doméstico $(77,7 \%)$. Entre as manifestações da violência, 96,3\% ocorreram com contato físico, em 60,8\% dos casos era reincidente e, além disso, $85,5 \%$ foram vítimas de agressão física em concomitância com a violência sexual. Em 
relação, pesquisa realizada em Teresina, evidenciou que $86,1 \%$ dos agressores eram pessoas conhecidas da família (SOARES et al., 2016). Destaca-se que em Teresina, estudo indicou que as violências ocorreram no domicílio da vítima $(46,7 \%)$, do agressor $(24,8 \%)$, entre outros locais da comunidade (13,6\%) (SOARES et al., 2016). Em estudos de nível nacional e internacional, aponta-se que as manifestações da violência sexual com contato são mais frequentes e geralmente aparecem acompanhadas por mecanismos de subjugação da vítima (FINKELHOR, ORMROD, CHAFFIN, 2009; SANTOS et al., 2015). Além disso, em Londrina, 92,9\% das vítimas apresentaram consequências físicas resultantes da violência sexual (MARTINS; JORGE, 2010). Em relação às características das denúncias, as mães apareceram como as principais denunciantes $(58 \%)$. Também ocorreram denúncias dos pais (16\%), outros familiares $(6,3 \%)$, pela escola $(8,6 \%)$ e setor policial $(7,4 \%)$ e a maioria foi realizada pessoalmente (92,6\%). Em pesquisa realizada no Rio Grande do Sul, 37,6\% das ocorrências foram denunciadas pelas mães da vítima (HABIGZANG et al., 2005).

No que concerne às características dos agressores sexuais de crianças e adolescentes, 97,5\% deles são do sexo masculino, 81,8\% com idades entre 19 e 64 anos, entretanto, 11,7\% apresentavam idade igual ou superior à 65 anos, e 6,5\% das violências sexuais foram praticadas por pessoas com idade menor ou igual a 18 anos. Sobre o estado civil, a maioria era solteiro $(54,2 \%)$ e 38,9\% eram casados. Em relação à escolaridade, 30,9\% possuem ensino médio completo, enquanto que $27,9 \%$ apresentam fundamental incompleto. A maioria dos agressores sexuais trabalhava $(80,7 \%)$, não usava substância psicoativa $(80,3 \%)$ e não apresentava histórico de detenção $(93,8 \%)$. Estudo realizado em Londrina, verificou que a maior frequência de agressores correspondeu à faixa etária de 25 a 39 anos $(44,1 \%)$ e acima de 40 anos (25,4\%) (MARTINS, MELLO JORGE, 2010). Ademais, em estudo realizado em Porto Alegre, com investigação da violência sexual identificou-se 27,5\% dos abusadores eram adolescentes, porém a predominância dos abusadores adolescentes foi do sexo masculino (61\%) concordância (PINCOLINI; HUTZ, 2014).

\section{CONSIDERAÇÕES FINAIS}

Em relação ao ano de 2015, foram notificados 81 casos de violência sexual contra crianças e adolescentes, registradas nas Delegacias de Polícia Civil e Especializadas (DEAM, DAI e DERCA) na cidade de Feira de Santana, Bahia. Em relação às características das denúncias, as mães apareceram como as principais denunciantes e grande parte foi realizada pessoalmente. No que se refere às características das vitimizações, a maioria das vítimas foi do sexo feminino, a faixa etária com maior número de ocorrências foi de 12 a 17 anos. Grande parte das vítimas frequentava a escola regularmente e moravam com a mãe. Enquanto isso, o abuso sexual constitui-se como a mais frequente, porém também houve casos de violência sexual com fins comerciais. $O$ contexto da violência extrafamiliar foi o mais frequente, e em relação ao vínculo com a vítima, a maioria dos agressores eram vizinhos ou pessoas da comunidade, o ambiente doméstico apresentou-se como o local mais frequente e com predominância da violência sexual com contato físico, com a presença da agressão física em concomitância. Em relação às características dos agressores, a maioria foi sexo masculino, com idade entre 19 e 64 anos, porém identificou-se a presença de agressores com idade menor ou igual a 18 anos. A maioria dos perpetradores maioria era solteiro, com ensino médio completo, trabalhava, não usava substância psicoativa, tampouco possuía histórico de detenção.

Em suma, a pesquisa atingiu os objetivos propostos, pois possibilitou a compreensão mais acurada da prevalência do fenômeno violência sexual, na cidade supracitada, as formas de apresentação dos abusos e principais formas de denúncia utilizadas pela população, o que pode funcionar como um dos instrumentos para que os órgãos competentes adotem estratégias para prevenção da violência e promoção de saúde para as vítimas e familiares. 


\section{REFERÊNCIAS}

ALMEIDA, T. M. C.; PENSO, M. A.; COSTA, L. F. ABUSO SEXUAL INFANTIL MASCULINO: O GÊNERO CONFIGURA O SOFRIMENTO E O DESTINO? Estilos da Clínica, v. 14, n. 26, p. 46-67, 2009.

BRASIL. Estatuto da criança e do adolescente. 7. ed. Brasília: Câmara dos Deputados, Edições Câmara, 2010, 225p.

BRASIL. Ministério da Saúde. Secretaria de Atenção à Saúde. Contextualização do Debate sobre Violência contra Crianças e Adolescentes. In: BRASIL. Ministério da Saúde. Violência faz mal à saúde. Brasília: Ministério da Saúde, 2004. Cap. 1, p. 14.

BRASIL. Sistema de Vigilância de Violência e Acidentes (VIVA), 2009, 2010, 2011.

Brasília: Ministério da Saúde, 2013, 164p.

FINKELHOR, D.; ORMROD, R. K.; TURNER, H. A. The Developmental Epidemiology of Childhood Victimization. J Interpers Violence, USA, v. 24, n. 5, p. 711-31, 2009.

HABIGZANG, L. F.; KOLLER, S. H.; AZEVEDO, G. A. Abuso Sexual Infantil e Dinâmica Familiar: Aspectos Observados em Processos Jurídicos. Psicologia: Teoria e Pesquisa, Brasília, v. 21, n. 3, p.341-348, 2005.

LEAL, M. L.L. PESTRAF - Pesquisa sobre Tráfico de Mulheres, Crianças e Adolescentes para fins de Exploração Sexual Comercial: Relatório Nacional - Brasil. Brasília: CECRIA; 2003. 280 p.

MARTINS, C. B. G.; JORGE, M. H. P. M. Abuso sexual na infância e adolescência: Perfil das vítimas e agressores em município do sul do Brasil. Texto Contexto Enferm, Florianópolis, v. 19, n. 2, p. 246-55, Abr-Jun, 2010.

MINAYO, M. C. de S.; ASSIS, S. G. de; NJAINE, K. Amor e violência: um paradoxo das relações de namoro e do 'ficar'entre jovens brasileiros. Editora Fiocruz, 2011.

MIRANDA K.C.L.; BARROSO M.G.T. A contribuição de Paulo Freire à prática e educação crítica em enfermagem. Rev. latino-americana de enfermagem, v.12, n.4, p. 631-5, 2014. MORAIS, N. A.; CERQUEIRA-SANTOS, E.; MOURA, A. S.; VAZ, M.; KOLLER, S.

Exploração Sexual Comercial de Crianças e Adolescentes: Um Estudo com Caminhoneiros Brasileiros. Psicologia: Teoria e Pesquisa, Jul-Set, v. 23, n. 3, pp. 263 272, 2007.

NEVES, A. S.; CASTRO, G. B.; HAYECK, C. M.; CURY, D. G. Abuso sexual contra crianças e adolescentes: reflexões interdisciplinares. Temas em Psicologia, v. 18, n. 1, p.99111, 2010.

PAPALIA, D.; OLDS, S. Desenvolvimento Humano. 7. ed. Porto Alegre: Artes Médicas, 2000. 873p.

PELISOLI, C.; PICCOLOTO, L. B. Prevenção do abuso sexual infantil: estratégias cognitivocomportamentais na escola, na família e na comunidade. Rev. Bras. Ter. cogn., v. 6, n. 1, p. 108-137, 2010.

PINCOLINI, A. M. F.; HUTZ, C. S. Abusadores Sexuais Adultos e Adolescentes no Sul do Brasil: Pesquisa em Denúncias e Sentenças Judiciais. Temas em Psicologia, v. 22, n. 2, 301311, 2014.

SANTOS, B. R. Guia escolar. Identificação de sinais de abuso e exploração sexual de crianças e adolescentes. Ministério da Saúde, 2011.

SENA, C. A.; SILVA, M. A.; FALBO-NETO, G. H. Incidência de violência sexual em crianças e adolescentes em Recife/Pernambuco no biênio 2012-2013. Ciência \& Saúde Coletiva, v. 23, n. 5, p. 1591-1599, 2018.

SOARES, E. M. R. et al. Perfil da violência sexual contra crianças e adolescentes. Revista Interdisciplinar, v. 9, n. 1, p. 87-96, 2016. 